\title{
The analysis of rainwater harvesting carrying capacity on water domestic supply for dwelling areas in Indonesia
}

\author{
Gatot Eko Susilo ${ }^{1}$, Muhammad Jafri ${ }^{1}$ \\ ${ }^{1}$ Civil Engineering Department, Universitas Lampung, Bandar Lampung, 35145, \\ Indonesia \\ gatot89@yahoo.ca
}

Received 01-02-2019; revised 22-02-2019; accepted 18-03-2019

\begin{abstract}
This research aims to promote the method to design rainwater harvesting facilities in Indonesian dwelling areas. The estimation of rainwater harvesting $(\mathrm{RWH})$ carrying capacity is undertaken using a simulation involving rainfall, inflow, and outflow data. The research was undertaken in Natar sub-district, Southern Lampung, Indonesia. Daily rainfall data from Branti Airport from 2013 to 2017 are used for the simulation. Research shows that houses in the study area can supply approximately $35 \%$ of their domestic water needs by applying RWH. This means that the support capacity of rainwater harvesting in the study area revolves around that value. The research also shows intensity of rainfall will greatly affect the carrying capacity of RWH. In addition to rainfall, the economic ability of a family plays an important role in planning the dimensions of a RWH facility in a house. Finally, maintenance of RWH facilities on a regular basis is important to ensure the operational effectiveness of RWH.
\end{abstract}

Keywords: RWH, carrying capacity, facility, house.

\section{Introduction}

The increasing of world population from year to year triggers the increasing number of needs that must be fulfilled. This condition encourages more and more natural resources needed both in quantity and quality. Among the various types of natural resources, water is one of the greatest natural resources for human benefit. In addition, for drinking, water is also needed by humans for various purposes of life such as bathing, washing, sanitation, gardening and others. The increasing population causes an increase in water demand. The increasing number of people from year to year around the world has led to an increase in water demand globally. Although most of the surface of the earth is covered by water, not all types of water can be used directly for various human needs. Clean and fresh water is basically the kind of water that humans really need. Increased access and the needs of clean water can cause serious problems. Reduced water reserves in the soil due to over-exploitation, and massive logging contribute to the future water scarcity.

Water scarcity is one of the main problems faced by many communities and the world in this century. The use of water has more than doubled the rate of population growth in the last century. Water scarcity is already felt and affecting every region of the world. More than half of the population live in areas that have an indication of water scarcity both physically and economically. Physical scarcity indicates the lack of water or water resources in an area. Water scarcity occurs economically 
when an area or country lacks the necessary infrastructure to take water from its source. Basically, on earth there is enough fresh water for seven billion people. But the problem of uneven distribution, waste in usage, pollution, and unsustainable management make water scarcity increasingly chronic in the world [1].

A 2014 study has surveyed water issues in about 500 major cities in the world. The survey finds that one of the world's four cities has water-related problems. Another source says, based on UN projections, by 2030 the world's freshwater demand will be 40 percent higher than availability. This condition is caused by several things, including climate change, human activities, and population growth. There are 12 major cities of the world experiencing a clean water crisis based on this study. Some of them are in the Asian continent of Bangalore (India), Beijing (China), Jakarta (Indonesia), and Tokyo (Japan). Several other cities are on the Continent of Europe namely Moscow (Russia), Istanbul (Turkey), and London (UK) including also in the city that has problems with clean water. Sao Paulo (Brazil), Mexico City (Mexico), and Miami (USA) are cities in the American continent with water problems. Cairo (Egypt) and Cape Town (South Africa) is a major city on the African continent that has recorded problems with water. Among the cities above, Cape Town is the most severely affected city of water crisis. Recent studies predict Cape Town's water reserves will be exhausted in early March 2018. The water crisis in Cape Town is partly due to very low rainfall in the last three years, as well as long drought. On the other hand, the population with water consumption continues to increase [2]. According to the UN, the world needs to make radical changes in managing water resources to meet future water needs. The search for new water source alternatives and water-saving aesthetic movements should be made to maintain the existence of water resources from scarcity and deficits.

One effort to overcome the problem of water scarcity is to conserve water. Water conservation is done by storing water during wet or rainy seasons and using the water for various purposes in the dry season. Water conservation philosophy is commonly used in water management in large reservoirs. Basically, the principle of water conservation can be done in many aspects. One of them is by utilizing rain water for various purposes. Utilization of rainwater at this time is better known as rainwater harvesting (RWH). RWH in some countries is applied to maintain the preservation of groundwater by directing the rainwater into the absorption wells to be impregnated into the ground as a recharge of groundwater. In some arid countries, the existence of RWH has existed since ancient times. In those countries people deliberately collected and stored rainwater for immediate use for various purposes of life such as drinking and sanitation. History records ancient peoples in the Indus valley in India and Pakistan had been using RWH technology for thousands of years. In many of the ancient cities remaining, many large stone barrels are found to collect rainwater that will be used to meet domestic and agricultural water needs. Some of these stone barrels still exist and are still used today. Another method used to collect rainwater is by collecting rainwater on the roof of the house and draining it into a reservoir. This method has been growing for hundreds of years in India and imitated by many world communities, especially the countries in Asia. Harvesting rain through the roof is known as Rooftop Rain Water Harvesting technique (RRWH). Various societies around the world have applied RWH. Developed countries such as the United States, Canada, Australia, Japan and some countries on the Europe Continent have used rainwater in modern ways. In other parts of the world, people use technology to pick up the rainwater. In developing countries in Africa and Asia, people use simple containers and systems in rainwater harvesting so as to reduce the quantity and quality of collected rainwater.

Indonesia is a country with a tropical climate. There are only two seasons in Indonesia which are dry season and rainy season. Indonesia is geographically located at $6^{\circ} \mathrm{LS}-10^{\circ} \mathrm{N}$ and $95^{\circ}$ East $-141^{\circ}$ East and lies between the Indian and the Pacific Ocean. Because of its location in a warm area of the equator then evaporation in the area occurs in large numbers. It is not surprising, therefore, that the rains continue to fall during the dry season. Indonesia is an archipelagic country with a greater number of oceans than land. Therefore, rain falls with high intensity. The average annual Indonesian rainfall is about 2000 to $3000 \mathrm{~mm}$. Nevertheless, the rainfall in Indonesia is not the same in every place. Western 
Indonesia gets more rain compared to eastern Indonesia. This condition occurs because the geography and topography of the regions in Indonesia are different from each other.

Many areas in Indonesia are rich in water resources. Domestic water needs are not difficult to overcome. On the opposite side, some regions in Indonesia have difficulties in getting clean water for the community. In coastal cities, people do not find fresh water sources. As a consequence, the people fulfil their domestic water needs by buying water from merchants coming from other places. Some swampy areas also share the same fate. People in the area are forced to buy water from other areas to meet domestic needs. Some of these areas have started to collect and utilize rainwater for domestic purposes by implementing rainwater harvesting. However, the rainwater harvesting facilities they make are not technical and very simple. Based on this, this research intends to promote the method for planning RWH facilities technically but simply. The proposed method is a method to estimate RWH's carrying capacity using a simulation involving rainfall data and water requirements as an inflow and outflow, respectively. The simulation philosophy is the water balance philosophy in RWH reservoir based on inflow and outflow behaviour. The focus of this research is the application of RWH in the dwelling areas.

\section{Material and Methods}

\subsection{Rainwater harvesting facility}

Today, rain water harvesting is widely applied to the purpose of using rainwater as an alternative domestic water supply. In general, rain harvesting methods are carried out with rooftop (RRWH). The RRWH facility is technically not a complicated system. In general, the RRWH sketch is illustrated in Figure 1. The mechanism in the RRWH system begins when the roof catches and collects rainwater. The caught rainwater is then collected through the gutters. The water-collecting gutters are equipped with strainers to remove relatively large debris such as leaves and gravel. The filtered water is then channeled into the reservoir by inlet pipe. The water contained in the reservoir is used for domestic water purposes. To ensure the quality of the rainwater to be used, the downstream portion of the reservoir is fitted with a filter comprising a nylon filter and activated carbon. The nylon filter serves as a small sediment and dust filter while activated carbon is used to remove odor from stored rainwater. A small water pump is used to drain water from the reservoir into the house. The pipeline from the reservoir to the house is called an outlet pipe. All components in the RRWH system require routine maintenance to ensure the smooth operation of the RRWH concerned.

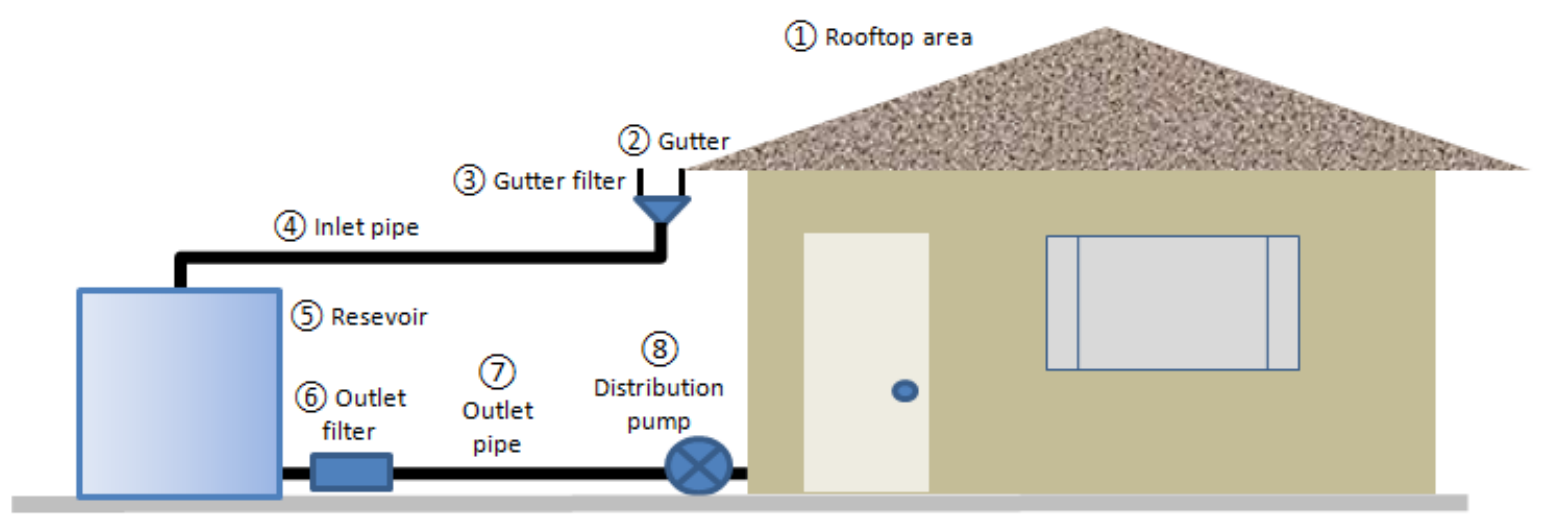

Figure 1. Rooftop rainwater harvesting (RRWH) facility

\subsection{Carrying capacity of $R W H$}

In general, urban communities in Indonesia meet their domestic water needs from shallow wells, drilled wells, or buying from local water companies or from individual merchants. When someone 
implements RWH at home or at work then some of the domestic water needs can be partially replaced by rain water. The ratio of the number of days in a year to which the domestic water supply is supplied by rain water with the total number of days in a year is expressed in a percentage. This percentage illustrates the power of RWH in supporting domestic water supply within a household or office. This percentage is referred to as the carrying capacity of RWH. For example, an RWH facility with a carrying capacity of $41 \%$ will be capable of supplying domestic water requirements of a home or office for 150 days from 365 days in the year. Carrying capacity of RWH varies from one location to another. This is because of the carrying capacity of RWH depends on the amount of inflow, outflow, and RWH facility dimension itself. To calculate the carrying capacity of a RWH facility, a simulation that involves inflow is daily rainfall with more than 10 years of data, roof area data, and reservoir dimension data. While to calculate the outflow data required the number of occupants of buildings and the amount of domestic water needs per capita.

The simulation to get the value of carrying capacity of RWH is based on the water balance philosophy in the reservoir [3][4]. The equation in the simulation is given as follows [5][6][7]:

$$
S_{t}=S_{t-1}+I_{t}-O_{t} \quad \text { for } \quad 0 \leq S_{t} \leq S_{\max }
$$

where $S_{t}$ is the reservoir volume on day $t\left(\mathrm{~m}^{3}\right), S_{t-1}$ is reservoir volume on day $t-1\left(\mathrm{~m}^{3}\right)$, It is inflow on day $t\left(\mathrm{~m}^{3}\right)$, Ot is outflow on day $t\left(\mathrm{~m}^{3}\right)$, and $S_{\max }$ is maximum storage capacity $\left(\mathrm{m}^{3}\right)$.

The inflow and outflow for day $t$ is calculated using formula 2 and 3, respectively:

$$
\begin{aligned}
& I_{t}=c \times R_{t} \times A \times 1000 \\
& O_{t}=n \times d
\end{aligned}
$$

In the inflow formula, $c$ is the runoff coefficient for roofs, the range value is ranged between 0.8 and 1.0 [8], $R_{t}$ is the volume of rainfall on day $t(\mathrm{~mm})$, and $A$ is the area of roof $\left(\mathrm{m}^{2}\right)$. On the other formula, outflow for day $\mathrm{t}\left(O_{t}\right)$ is formulated as a function of number of building occupants $(n)$ and water demand per person per day $(D)$.

\subsection{Case study}

The case study of the research is undertaken in Natar sub-district, Southern Lampung, Indonesia. Natar is an area of $213.77 \mathrm{~km}^{2}$ and a population of 186,372. It is an emerging area from rural to urban. Natar is a flat plain that is largely dominated by plantations and settlements. As a developing region, the availability of water is a necessity that must be considered for the survival of urban and community life. During this time the Natar people rely on domestic water supply from shallow wells and boreholes. There is no public water company in the area. In the next few years, Natar will begin to experience a clean water crisis in the dry season. Therefore, introducing rainwater harvesting to meet domestic water needs is an important thing to do. This research aims to calculate the carrying capacity of RWH for home and office buildings in the Natar region.

For research purposes, the data used for the simulation are:

- Daily rainfall data taken from Branti Airport which is administratively located within the Natar region. The data length is 5 years from 2013 to 2017.

- Roof area data

- Data on the number of building occupants

- Data of domestic per capita water demand (based on Ministry of Public Works of the Republic of Indonesia per capita domestic water requirement for Natar city is $90 \mathrm{~L} /$ day) 


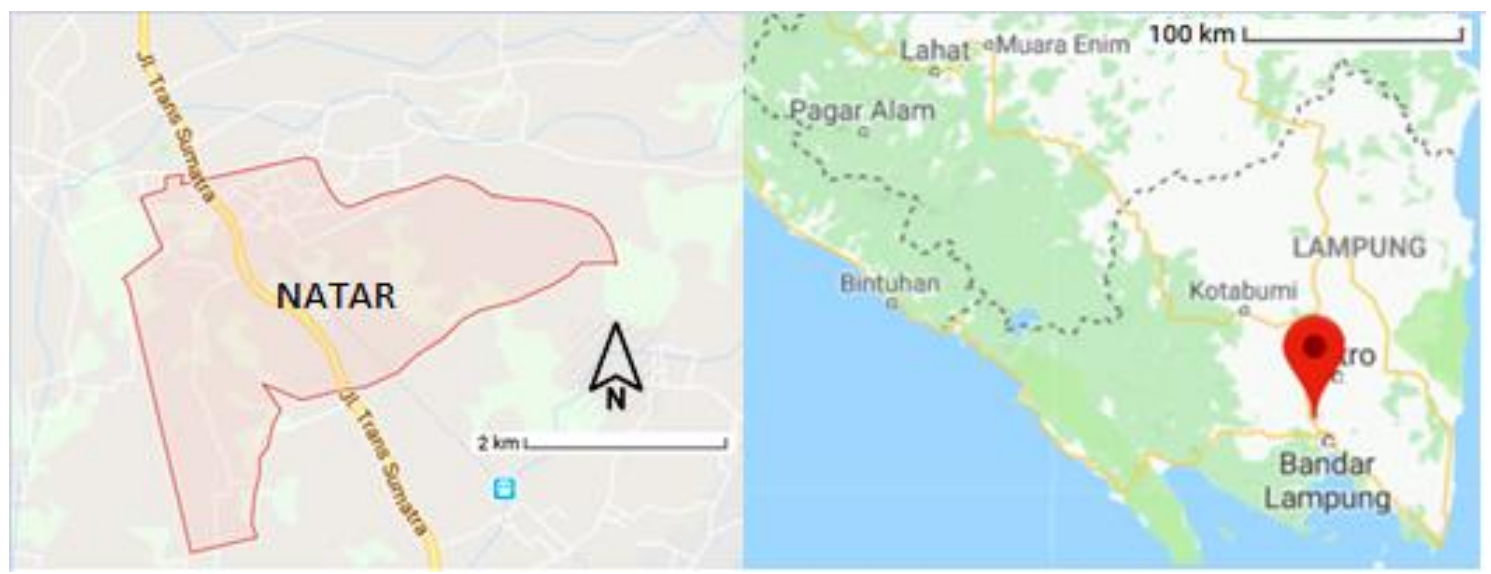

Figure 2. Location of the study

\subsection{The simulation}

Simulation is undertaken in order to calculate carrying capacity of RWH. The example of simulation procedures is illustrated in the table as follows:

Table 1. An Example of simulation procedures

\begin{tabular}{ccccccccc}
\hline Date & $\mathrm{R}(\mathrm{mm})$ & $\mathrm{A}\left(\mathrm{m}^{2}\right)$ & $\mathrm{C}$ & $\mathrm{Inf} .\left(\mathrm{m}^{3}\right)$ & $\mathrm{n}$ & $\mathrm{D}\left(\mathrm{m}^{3}\right)$ & Outf. $\left(\mathrm{m}^{3}\right)$ & $\mathrm{S}\left(\mathrm{m}^{3}\right)$ \\
\hline$(1)$ & $(2)$ & $(3)$ & $(4)$ & $(5)$ & $(6)$ & $(7)$ & $(8)$ & $(9)$ \\
\hline 01-Jan-13 & 36.5 & 30 & 0.9 & 0.99 & 4.00 & 0.09 & 0.36 & 0.63 \\
02-Jan-13 & 68.0 & 30 & 0.9 & 1.84 & 4.00 & 0.09 & 0.36 & 2.10 \\
03-Jan-13 & 0.0 & 30 & 0.9 & 0.00 & 4.00 & 0.09 & 0.36 & 1.74 \\
04-Jan-13 & 12.2 & 30 & 0.9 & 0.33 & 4.00 & 0.09 & 0.36 & 1.71 \\
\hline
\end{tabular}

The procedures above can be described as follows:

- Column 1 is the date on day $t$ simulation

- Column 2 is the daily rainfall on day $t$ (in $\mathrm{mm}$ )

- Column 3 is the area of the roof $\left(\right.$ in $^{2}$ )

- Column 4 is the flow coefficient on the roof (set at 0.9)

- Column 5 is the volume of inflow on day $t\left(\right.$ in $\left.^{3}\right)$ calculated by the formula (2)

- Column 6 is the number of building occupants

- Column 7 is daily per capita water requirement ( $\left(\mathrm{n}^{3}\right)$

- Column 8 is the outflow volume (in $\mathrm{m}^{3}$ ) on day $t$ calculated by the formula (3)

- Column 9 is the volume of water in the reservoir $\left(\mathrm{in}^{3}\right)$ that is calculated by the formula (1)

Here is an example of calculation:

To get the volume of water in the reservoir on Jan 4, 2013 then:

- $\quad S(\operatorname{Jan} 4,2013)=$ Inflow $(\operatorname{Jan} 4,2013)-$ Outflow $(\operatorname{Jan} 4,2013)+S(\operatorname{Jan} 3,2013)$.

- If $S(\operatorname{Jan} 4,2013)<0$ then $S(\operatorname{Jan} 4,2013)=0$

- If $S(\operatorname{Jan} 4,2013)>S_{\max }$ then $S(\operatorname{Jan} 4,2013)=S_{\max }$, or in other words the $S$ value (January 4 , 2013) must be between 0 and $S_{\max }$.

Then the calculation can be done for another date. The carrying capacity of RWH is the number of days, whose the $S>0$, divided by the number of days in the year which is 365 or 366 . 


\section{Result and Discussion}

\subsection{Results of the research}

Figure 3 illustrates daily rainfall data from Branti Airport from 2013 to 2017. The data shows rain accumulation between April and October. Conversely, between May to September the rain did not fall too much. These data indicate that the area under study follows the usual rain patterns in Indonesia. In most parts of Indonesia, the rainy season occurs between October and April, and the dry season occurs between May and September. The intensity of rainfall in 2013, 2014, 2015, 2016, and 2017 is 2465.2 $\mathrm{mm}, 1682.5 \mathrm{~mm}, 1628.1 \mathrm{~mm}, 2317.6 \mathrm{~mm}$, and $1825.1 \mathrm{~mm}$, respectively. The year 2014, 2015 and 2017 are included into dry year with rainfall intensity of less than $2000 \mathrm{~mm}$. On the other side, year of 2013 and 2016 are included into wet years with rainfall intensity of more than $2000 \mathrm{~mm}$.

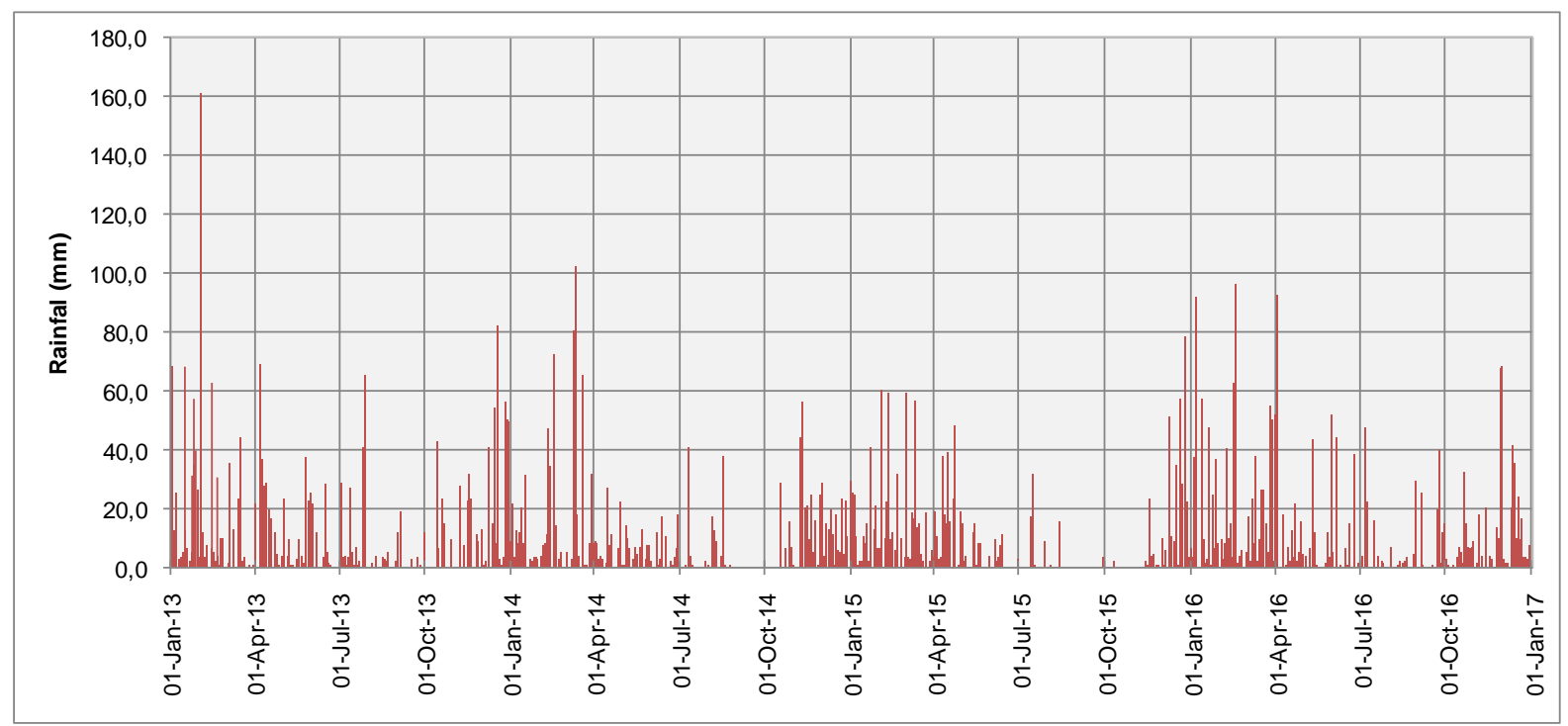

Figure 3. Daily rainfall of Branti Airport for the simulation

Using the daily rainfall data above, a simulation to find RWH carrying capacity of a residential house is implemented. Results of simulation are shown on Figure 4. In Indonesia, the type of house is usually based on the size of the building. For example, type 21 house means a house with an area of $21 \mathrm{~m}^{2}$. Building area is considered equal to the roof area of the house. Common types of houses in Indonesia are: type 21 , type 36 , type 45 , type 60 , and type 70 . House type 21 and type 36 are usually chosen by low-income families. While upper middle income families prefer to choose the type 45 , type 60 , and type 70. Type 45 is the most favourite type of house in Indonesia. House type 70 is a type of house that usually chosen by high economic class or a wealthy family. On the other hand, houses in Indonesia are usually occupied by 4 to 6 residents consisting of father, mother, and 2 or 3 children. Assuming that each house in the study area is generally a 45 type house occupied by 5 people, then based on the graph in Figure 4 the carrying capacity of RWH in each house is 33 to $41 \%$ for $S_{\max }$ between 2 to $8 \mathrm{~m}^{3}$. The simulation results above show the carrying capacity of RWH to provide domestic water supply per capita of 90 litres per day. Generally, in Indonesia people only use rain water for sanitation activities. Sanitation activities require only about $80 \%$ of the total domestic water need [10]. Therefore, if RWH water is only used for sanitation purposes then the carrying capacity of RWH will increase as shown in Figure 5. 

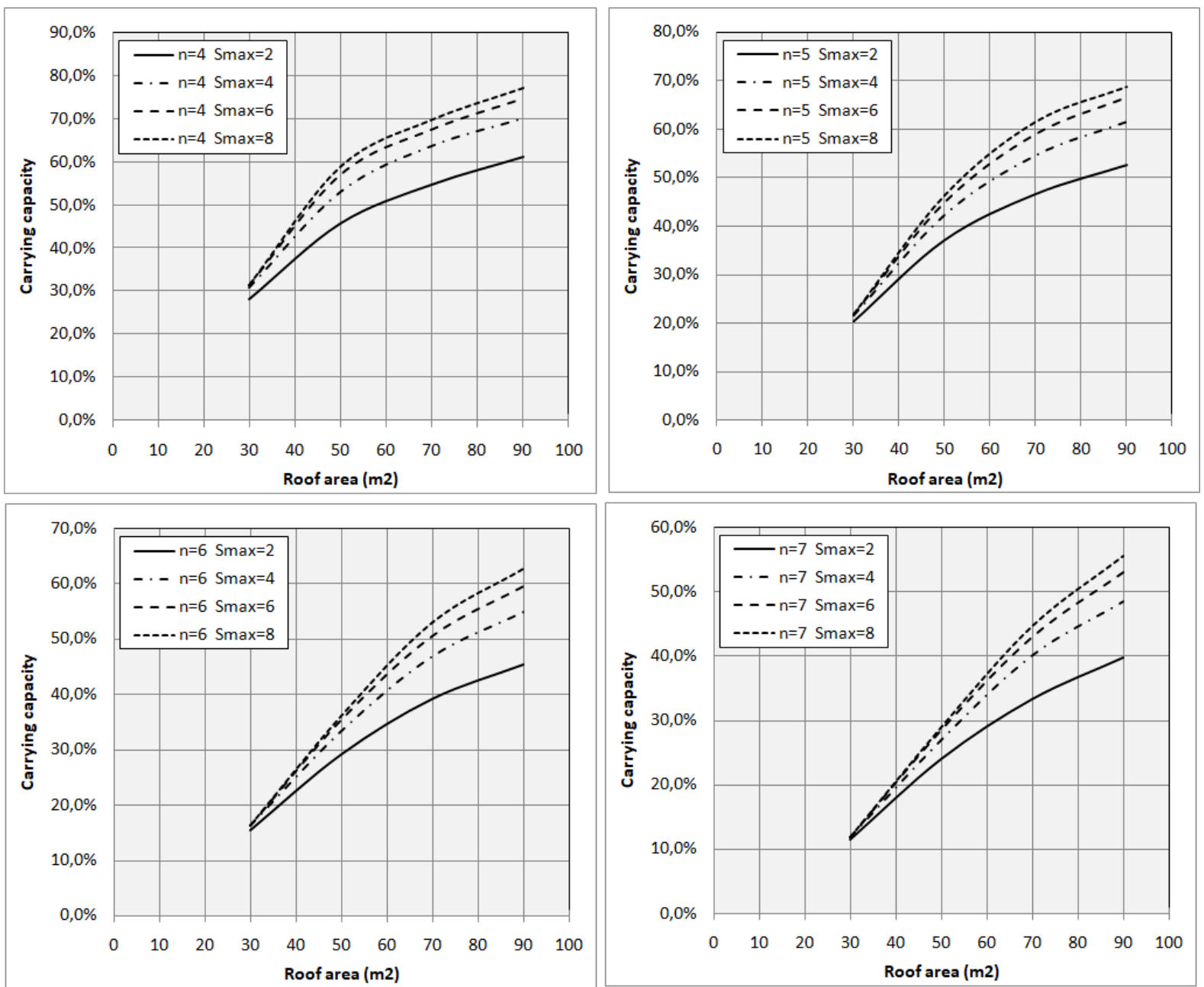

Figure 4. Carrying capacity of RWH for various values of $A$, $n$, and $S_{\max }$.

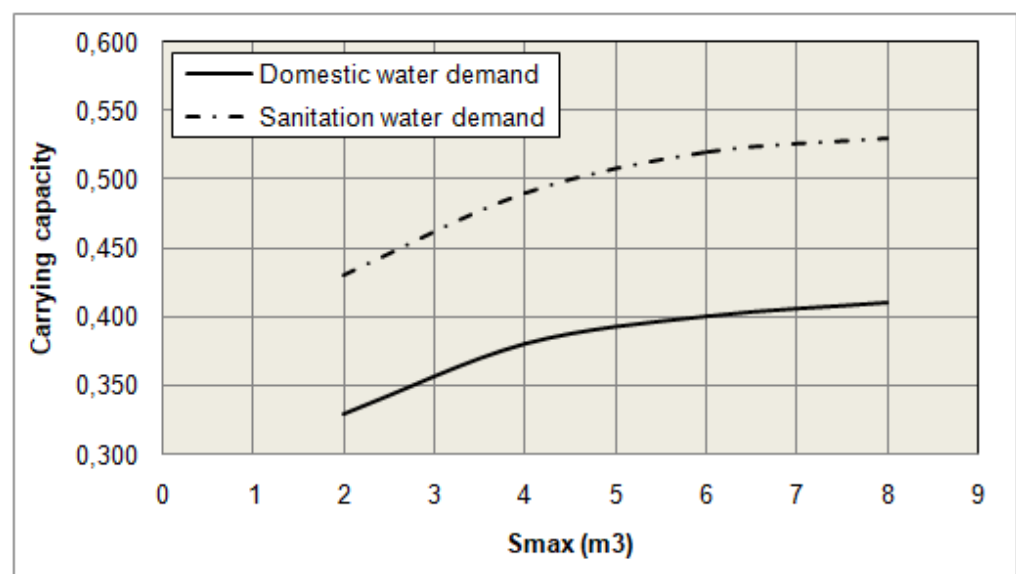

Figure 5. Carrying capacity of RWH for house type 45 , occupied by 5 people, with various values of maximum capacity of reservoir $\left(S_{\max }\right)$

Based on Figure 4 fluctuations in the volume of water in the reservoir for each $S_{\max }$ is presented in Appendix 1. The fluctuation of water volume in the reservoir as shown in Appendix 1 shows a pattern that is not very different from one another. The patterns formed follow the pattern of rainfall in the 
area concerned. This shows that rainfall is a parameter that has a very strong effect on the value of RWH carrying capacity. Rainfall is also an independent parameter that can determine the maximum value of a RWH carrying capacity. In areas with very high rainfall intensities, the maximum capacity of reservoir $\left(S_{\max }\right)$ and the roof area are parameters that also determine the maximum value of a RWH carrying capacity. In contrast, in areas where rainfall intensity is small, rainfall is the dominant parameter and other parameters do not significantly affect the maximum value of a RWH carrying capacity. The carrying capacity of RWH each year varies based on the number of rainy days and their intensity. The carrying capacity of RWH each year varies based on the number of rainy days and rainfall intensity. Based on the simulation results, the dry years produce a smaller RWH carrying capacity than the wet years. Table 2 illustrates the example of RWH carrying capacity for each year with the same $A=45 \mathrm{~m} 2$ and $\mathrm{n}=5$ people with various Smax. The contents of the table clearly indicate that the carrying capacity of RWH in wet years (2013 and 2016) is greater than one in the dry years $(2014,2015$, and 2017). The average carrying capacity of RWH in wet years ranges from 45 to $46 \%$ while in dry years it ranges from 30 to $35 \%$.

Table 2. RWH carrying capacity for each year for $\mathrm{A}=45 \mathrm{~m}^{2}, \mathrm{n}=5$ people, with various $S_{\max }$.

\begin{tabular}{cccccc}
\hline Year & \multicolumn{4}{c}{ Maximum capacity of reservoir (Smax) in $\mathrm{m}^{3}$} & \multirow{2}{*}{ Average } \\
\cline { 2 - 5 } & 2 & 4 & 6 & 8 & \\
\hline 2013 & $39.2 \%$ & $45.5 \%$ & $47.1 \%$ & $48.5 \%$ & $45.1 \%$ \\
2014 & $27.1 \%$ & $32.9 \%$ & $35.9 \%$ & $37.0 \%$ & $33.2 \%$ \\
2015 & $29.9 \%$ & $31.0 \%$ & $31.0 \%$ & $31.0 \%$ & $30.7 \%$ \\
2016 & $38.1 \%$ & $44.9 \%$ & $49.9 \%$ & $51.2 \%$ & $46.0 \%$ \\
2017 & $32.3 \%$ & $35.9 \%$ & $35.9 \%$ & $35.9 \%$ & $35.0 \%$ \\
2013 & $39.2 \%$ & $45.5 \%$ & $47.1 \%$ & $48.5 \%$ & $45.1 \%$ \\
\hline
\end{tabular}

One important thing to do in order to ensure the effectiveness of RWH implementation is regular maintenance of RWH facilities. Cleaning the roof of the house from dirt such as leaves, animal waste, and gravel, should be implemented to ensure the quality of rain water that fell to the roof. This activity can be done once or twice before the rainy season. Clearing gutters from leaves or other debris may have to be more frequent to do especially in areas with many trees. Sometimes the leaves fall and are carried by the wind into the gutter. The existence of these leaves on the gutters will clog the gut hole and inhibits the water entering into the inlet pipe. Cleaning the gutters can be done once in a week or two weeks in the rainy season, depending on the amount of dirt that disrupts the effectiveness of the gutter. In the dry season the clearance of the gutter is done once in two weeks or a month depending on the amount of rain in the dry season. Cleaning the reservoir can be done once in two months to remove the fine sediment accumulated at the bottom of the reservoir. The filter on the outlet pipe can be replaced within 3 to 6 months depending on the amount of filtered filth. Filters can be purchased on the market at an affordable price.

\section{Conclusions}

Analysis to investigate the carrying capacity of rainwater harvesting for clean water supply at the household level has been completed. The research produced several conclusions as follows:

1. The results show that in general the houses in the study area can supply approximately $35 \%$ of their domestic water needs by applying RWH. Houses with larger size and larger RWH facilities will be able to supply their domestic water with larger quantities. 
2. The above discussions show that the implementation of RWH is an effective way to address future water shortage problems in Indonesia. The simulations in this study indicate that the carrying capacity of RWH in a house can be improved by modifying the dimensions of the RWH facility. The parameters in the RWH design can be changed as needed. The irreversible parameter is the intensity of rainfall.

3. The economic ability of a family plays an important role in planning the dimensions of a RWH facility. RWH facilities with larger dimensions tend to produce a larger RWH carrying capacity. Thus the availability of water will become more assured.

4. The intensity of rainfall will greatly affect the carrying capacity of RWH. Rainfall intensity is a parameter that can be used as a reference in designing the dimensions of an RWH facility. In addition to rainfall, investment cost and space availability are the things to consider in planning the RWH dimension.

5. Maintenance is an important part of RWH implementation. Maintenance of RWH facilities on a regular basis will ensure the smooth operation of RWH.

\section{Acknowledgements}

The authors wish to express their deep gratitude to the Civil Engineering Department, University of Lampung for their support in this research. The authors also wish to express their gratitude to the students involved in completing this research.

\section{References}

[1] United Nation Department of Economic and Social Affair (UNDESA). 2014. Water scarcity. United Nation Department of Economic and Social Affair (UNDESA) article. Website: http://www.un.org/waterforlifedecade/scarcity.shtml. [Accesssed Jan 25, 2019]

[2] British Broadcasting Coorporation (BBC). 2018. Water scarcity threatens 11 cities in the world, Jakarta one of them. Website: https://internasional.kompas.com/read/2018/02/12/16071851/ kelangkaan-air-ancam-11-city-in-the-world-jakarta-one only? Page = all. [Accesssed Jan 27, 2019].

[3] Khastagir, A. and Jayasuriya, N. 2010. Optimal sizing of rain water tanks for domestic water conservation. Journal of Hydrology, 381(3-4), pp. 181-188.

[4] Kahinda, J.M., Taigbenu, A.E. and Boroto, R.J. 2010. Domestic rainwater harvesting as an adaptation measure to climate change in South Africa. Physics and Chemistry of the Earth, Vol. 32(15-18), pp. 1050-1057.

[5] Susilo, G.E., Yamamoto, K. and Imai, T. 2011. The identification of rainwater harvesting potency in supporting freshwater availability under the effect of El Nino. Proceeding IWA ASPIRE International Conference, October 2011, Tokyo - Japan.

[6] Susilo, G.E. 2015. Experience in rainwater harvesting application at household scale in Bandar Lampung, Indonesia. Proceeding of The 1st Young Scientist International Conference of Water Resources Development and Environmental Protection, Malang, 5-7 June 2015

[7] Susilo, G.E., Efendi, R., Desmawati, E. and Nalaralagi, A. 2017. Promoting rainwater harvesting as an alternative of freshwater source for public sanitation. Journal of Asian Institute of Low Carbon Design (2017)

[8] Fewkes, A. 1999. The use of rainwater for WC flushing: the field testing of a collection system. Building and Environment, 34(6), 765-772.

[9] Fair, G.M., Geyer, J.C. and Okun, D.A. 1971. Elements of Water Supply and Wastewater Disposal. Second Edition, John Wiley \& Sons, Inc. and Toppan Company, Ltd., New York.

[10] Poedjiastoeti, H. and Syahputra, B. 2006. Determination of the maximum peak hour and daily maximums on the domestic water use pattern in Kalasan, Sleman, Yogyakarta. Proceeding of Lecturer Research, Research Institute of Sultan Agung University, Yogyakarta, Indonesia. 